\title{
Pathways to Improving Nutrition among Upland Farmers through Nutrition-Sensitive Agriculture Interventions: A Case from Northern Laos
}

\author{
Indu K. Sharma 1,2,*iD, Dirk Essink ${ }^{1}$, Victoria Fumado ${ }^{2,3}$, Ranjan Shrestha ${ }^{4}$, Zefanya D. Susanto ${ }^{1}$ \\ and Jacqueline E. W. Broerse ${ }^{1}$
}

check for updates

Citation: Sharma, I.K.; Essink, D.; Fumado, V.; Shrestha, R.; Susanto, Z.D.; Broerse, J.E.W. Pathways to Improving Nutrition among Upland Farmers through Nutrition-Sensitive Agriculture Interventions: A Case from Northern Laos. Sustainability 2021, 13, 13414. https://doi.org/10.3390/su132313414

Academic Editors: Libby Swanepoel, Jessica E. Raneri and Arminda Paço

Received: 3 October 2021

Accepted: 23 November 2021

Published: 3 December 2021

Publisher's Note: MDPI stays neutral with regard to jurisdictional claims in published maps and institutional affiliations.

Copyright: (c) 2021 by the authors. Licensee MDPI, Basel, Switzerland. This article is an open access article distributed under the terms and conditions of the Creative Commons Attribution (CC BY) license (https:/ / creativecommons.org/licenses/by/ $4.0 /)$.
1 Athena Institute, Faculty of Science, Vrije Universiteit of Amsterdam, 1081 HV Amsterdam, The Netherlands; d.r.essink@vu.nl (D.E.); z.d.susanto@student.vu.nl (Z.D.S.); j.e.w.broerse@vu.nl (J.E.W.B.)

2 Barcelona Institute for Global Health (ISGlobal), University of Barcelona, 08007 Barcelona, Spain; victoria.fumado@sjd.es

3 Barcelona Saint John of God University Hospital, University of Barcelona, 08950 Barcelona, Spain

4 SNV Country Office, Vientiane P.O. Box 9781, Laos; ranjanshrestha@snv.org

* Correspondence: i.k.sharma@vu.nl

\begin{abstract}
While there is an increased awareness of the role of nutrition-sensitive agriculture (NSA) interventions on nutrition, the studies that investigate holistic pathways from interventions to nutrition outcomes are inadequate. We aimed to understand these pathways to improved nutrition from the Enhancing Nutrition of Upland Farming Families (ENUFF) Project implemented in northern Laos. We applied an embedded case study design by recruiting 101 participants representing implementers, school and private sector representatives, and beneficiaries, of which 34 participated in interviews and 68 participated in 11 FGDs. This was supplemented by a desk review of project documents. We analyzed the data using a directed content analysis across five pathways using a published framework on impact pathways from NSA interventions to nutrition outcomes. The project contributed to nutrition mainly through three core pathways-food production, nutrition and WASHrelated knowledge, and agricultural income, supported by strengthening local institutions within the project's scope. While it is evident that the project contributed to empowering women by saving their time and increasing income, further study is needed to investigate the translation of these aspects to nutrition-related practices. We also suggest the need to sustain the capacity of local institutions and their engagement beyond the project cycle. To enhance the effectiveness of NSA interventions on nutrition, there is a need to design and implement intervention package with multiple pathways and tailored strategies based on nutrition outcomes, the envisaged pathways, geographical context, and factors affecting these.
\end{abstract}

Keywords: multisector nutrition; convergence; nutrition-sensitive; qualitative study; Laos; factors; traditional food systems; malnutrition

\section{Introduction}

The role of the agriculture sector in addressing poor diets and consequent malnutrition has been previously studied [1,2]. Optimising the contribution of agriculture to address malnutrition requires a nutrition-sensitive approach in designing and implementing the interventions, simultaneously addressing its multiple determinants [3,4]. There is, therefore, the need to make the agricultural sector nutrition-sensitive by redesigning conventional agricultural interventions to nutrition-sensitive agriculture (NSA) interventions, which explicitly incorporate nutrition objectives and actions [2,5].

Past studies have suggested that NSA can address malnutrition through multiple pathways [2,3,5]: improving food production [2,3,5], raising income level enabling the purchase of nutritious foods $[2,3,5]$, empowering women to make nutrition-related decisions [2,3,5], increasing nutrition-related knowledge [3], strengthening local institutions [3], 
and food price [2]. NSA can appropriately fit in the context of low- and middle-income countries (LMICs), as most of the population depends on agriculture as the primary source for their livelihood $[2,6]$.

While there is abundant evidence on the impact of NSA interventions on nutrition and specific pathways to such effects, studies that investigate a holistic examination of impact pathways are limited. Our recent review highlighted research gaps on the pathways on women's empowerment, income-expenditure and strengthening of local institutions, suggesting more research [3]. Furthermore, fragmentation of the evidence-based intervention package across multiple studies has limited the understanding of the holistic pathways and the effects [3]. There is thus a need to map the comprehensive impact pathways that lead from NSA interventions to better nutrition outcomes by assessing the effects of the interventions on nutrition and detailing the pathways from the interventions to the effects.

In this article, we report on a case study conducted in Lao PDR (hereafter Laos). Laos is one of the LMICs facing a high burden of malnutrition, with undernutrition rates higher than the global average. As per the Lao social indicator survey 2017, 33\% of children under the age of five years are low height-for-age (stunted), $21 \%$ are low weight-for-age (underweight), and $9 \%$ are low weight-for-height (wasted) [7]. These rates are higher than global average rates on undernutrition, for example, $21.9 \%$ of children under the age of five years are low height-for-age and 7.3\% have a low weight-for-height [8]. Despite the reduction in poverty and significant economic growth over the last decade [9], the country experiences slow progress in reducing malnutrition among children and women [10]. Moreover, $40 \%$ of women of reproductive age are anaemic [11]. Persisting geographical and economic inequalities further exacerbate the problem. The country faces one of the highest inequalities in malnutrition rates by wealth and location, e.g., the difference in stunting rates between the richest and poorest, and urban areas and rural areas are $40.9 \%$ and $21.2 \%$, respectively [8].

There is a need for the agriculture and food (agri-food) system in Lao PDR to be more nutrition-sensitive to address inadequate diet and malnutrition. The traditional agri-food system in Laos exhibits subsistence production with rice as the main staple [12]. The food system in upland villages in northern Laos traditionally relies on shifting cultivation to produce food [13]. Subsistence production is transitioning to commercialized agriculture focused on annual cash crops cultivation and is developing as a means for livelihoods [13,14]. The insufficient production diversity seems to be a reason for inadequate diet. A study found that more than half of the study population were food insecure [15]. The study highlighted that eighty-eight percent of average calorie intake per capita came from rice whereas there was less consumption of other foods such as meat, eggs, fats, and oils [15]. Wild foods are important sources of subsistence as several populations depend on such foods to fulfill their nutrition needs as well as income [14]. Food diversification and increased access to nutrient-rich foods, such as vegetables, meat, and fish, is necessary to address inadequate diet and consequent malnutrition in Lao PDR [12]. NSA approach can tap into the traditional agri-food system to make the system nutrition-sensitive [16] by incorporating nutrition across the pathways from food production to food consumption.

The government of Laos has committed to achieving the second Sustainable Development Goal—end hunger, achieve food security and nutrition by 2030 [17]. It has developed a road map to promote people's health by eliminating food insecurity and malnutrition as envisaged in the National Nutrition Strategy to 2025 and Plan of Action 2016-2020 [10]. NSA is one of the priorities of the National Nutrition Strategy to 2025 and Plan of Action as the country recorded a significant investment of USD 27.2 million on NSA in 2018 and is home to over 11 registered NSA projects [18].

Despite the implementation of several NSA interventions in Laos, studies on the pathways from NSA interventions to nutrition outcomes are surprisingly scarce. The country-specific studies related to NSA are centred on agricultural production $[13,19,20]$. To our knowledge, only one paper investigated the role of home gardens in improving nutrition in 2004 [21]. However, as NSA interventions and their effects are context-specific, 
decision-making on designing and implementing the interventions to address malnutrition can benefit from more contextual evidence on impact pathways [22]. Furthermore, none of the studies reviewed by a recent systematic review on NSA interventions' impact pathways represented Laos [3]. It is, thus, crucial to understand through what pathways and how, such interventions are progressing towards achieving nutrition outcomes in Laos.

This study aims to understand impact pathways from NSA interventions to improved nutrition outcomes in upland farming areas of northern Laos, using the Enhancing Nutrition of Upland Farming Families (ENUFF) Project as a case. Since April 2016, the ENUFF Project has been implementing a multi-sectoral programme, including NSA interventions in Northern Laos to improve nutrition outcomes in remote and ethnically diverse upland farming communities [23]. We expect that the results of this research will contribute to enhancing the effects of NSA interventions on nutrition outcomes in the context of the ENUFF Project, Laos, and other LMICs.

\section{Materials and Methods}

\subsection{Study Design}

We used an embedded qualitative case study design to explore the pathways from ENUFF's NSA interventions to nutrition outcomes. Because of the embedded case study design [24], we analysed four villages as separate units of analysis. These were later embedded into a holistic case. The case study was conducted using qualitative data supplemented by a desk review of key project documents. The qualitative data were collected by purposively sampling four groups of participants: project implementers, beneficiaries, school representatives and private sector representatives.

\subsection{Project Description}

The ENUFF Project aims to: improve dietary practices among children under five years of age and women of reproductive age by increasing availability and accessibility of diverse nutritious foods; reduce the incidence of water, sanitation \& hygiene (WASH) related diseases; and strengthen a conducive institutional framework at the subnational levels [25]. The project activities are divided into two phases. The first phase (April 2016-June 2020) targeted 4000 households from 40 villages [25]. The second phase (July 2020-June 2024) includes 2000 additional households from 20 more villages [25]. All of these villages belong to remote and ethnically diverse upland farming communities of four districts: Xiengkhor and Viengxay districts of Houaphanh province and Nga and Beng districts of Oudomxay s province [25]. This research is based on the interventions from the first phase. Funded by the Swiss Agency for Development and Cooperation (SDC), the Netherlands Development Organisation (SNV) implemented the project together with Agrisud International, a local NGO named Rural Development Agency (RDA), and government counterparts. The government partners involved at the sub-national level are the Provincial Health Departments, Provincial Agriculture and Forestry Offices and Lao Women's Union [25]. The respective district offices of these provincial offices implement the activities by establishing the District Nutrition Team that comprises ten members from District Health Office, District Agriculture and Forestry Office, and District Lao Women's Union. The project also established a village-level nutrition team (VNT) that comprises seven volunteers responsible for following up on the adoption of practices by beneficiaries.

ENUFF Project's convergence approach combines agricultural production activities with social behaviour change communication to promote optimal nutrition and water, sanitation and hygiene (WASH) practices [23]. Besides the target households, the project provided school gardening support and nutrition and hygiene WASH education during the first phase. The school-based activities were terminated for a certain period as collaboration with the Department of Education could not be established. Box 1 gives a summary of the activities; more information can be accessed from elsewhere [23,25-27]. 
Box 1. Brief description of different components of the ENUFF project.

Agricultural component: The agriculture component comprised of crop and livestock production.

Crop production-The project delivered intensive training on home gardening, and provided inputs to a few motivated pilot farmers who possessed sufficient land near household premises and labour to take care of the garden. Furthermore, a few beneficiaries who had sufficient resources—land, water, labour, and equipment—received inputs for establishing a greenhouse. The project provided training on fruits production and saplings of banana, mango and papaya trees, and also delivered rice and legumes production activities to some extent. Livestock production: Livestock activities comprised training on rearing livestock and inputs such as fence and fodders and paid vaccination.

Marketing component: The project also imparted knowledge on the importance of selling surplus agricultural products for income to make nutrition-related expenses.

Nutrition and WASH social behaviour change communication component: This comprised four activities triggering to educate all community members on nutrition; monthly cooking demonstrations targeted to pregnant women and caretakers of children under five years of age; counselling on optimal nutrition and WASH practices to households with pregnant women and children under two years; and WASH infrastructural support. The WASH infrastructures support comprised rehabilitation or construction of water systems (gravity-fed water systems) in selected villages and provision of training on toilet construction to village-based volunteers.

Women empowerment component: The project also integrated gender to increase women's participation in activities and their empowerment.

\subsection{Research Sites}

The primary data of this embedded case study was collected from ENUFF project beneficiaries in selected implementation villages as well as implementers representing the village, district, province and national levels. The villages selected for this study are Namkhong and Phonsa At from Beng district and Mokloy and Phouko from Nga district. As indicated in Table 1, these villages were selected based on three criteria: high rates of stunting, villages' typology, and equal representation of the districts [28]. The villages represented three typologies: a remote village with extensive upland agriculture, an accessible village with intensive commercial agriculture and a subsistence-oriented village with lowland agriculture. One more remote village with extensive upland agriculture was selected to make the selection representative to the districts, which led to four villages meeting the inclusion criteria.

Table 1. Characteristics of villages selected for the study.

\begin{tabular}{|c|c|c|c|c|}
\hline SN & Village & Stunting [28] & Village Type [28] & District \\
\hline 1 & Namkhong & $60 \%$ & $\begin{array}{l}\text { Type } 1 \text { Remote villages with extensive } \\
\text { upland agriculture }\end{array}$ & Beng \\
\hline 2 & $\begin{array}{c}\text { Phonsa } \\
\text { At }\end{array}$ & $71 \%$ & $\begin{array}{l}\text { Type } 2 \text { Accessible villages with intensive } \\
\text { commercial agriculture }\end{array}$ & Beng \\
\hline 3 & Mokloy & $77 \%$ & $\begin{array}{l}\text { Type } 3 \text { Subsistence-oriented villages } \\
\text { with lowland agriculture (paddy) }\end{array}$ & Nga \\
\hline 4 & Phouko & $61 \%$ & $\begin{array}{l}\text { Type } 1 \text { Remote villages with extensive } \\
\text { upland agriculture }\end{array}$ & Nga \\
\hline
\end{tabular}

\subsection{Participants and Recruitment}

To gain holistic perspectives on the pathways, we ensured geographical and stakeholder representation. We recruited four categories of participants from different geographical sites and levels representing: implementers, beneficiaries, school representatives and private sector representatives (vegetable- or seed-sellers). The implementers were the participants involved in the execution of the project. They represented government and non-government sectors and covered the national, provincial, district and village levels. The school and private sector representatives were not involved in the implementation. We could access a private sector representative from one district only and a seed seller at the 
village level who was also a beneficiary. The beneficiaries participated in at least one of the following activities: information session on agriculture production and nutrition/WASH communication for triggering, intensive training and inputs on home gardening and/or greenhouse, cooking demonstration and/or nutrition/WASH communication. Some of the beneficiaries were indirect beneficiaries, as they did not directly participate in the activities but received benefits either through their parents who benefited from the project or through information materials. While we contacted the project implementers to identify the implementers and some beneficiaries, we also applied the snowball method to recruit more beneficiaries and key informants. As indicated in Table 2, we recruited 101 participants representing four levels, national, provincial, district and village. Of these, 58 were beneficiaries, comprising 57 females and one male. The male member was the husband of a female beneficiary and a beneficiary of greenhouse activities, recruited to learn about vegetable production and women empowerment as recommended by the female beneficiary. The labelling of the participants mentioned in the table is based on each category of participants and will also be used in the results sections:

INI: Implementers at national level-interview

INF: Implementers at national level-FGD

IP: Implementers at the province level

ID: Implementers at the district level

IV: Implementers at village level

PR-Private sector representative

SR-School representative

BI-Beneficiaries-interview

BF-Beneficiaries-FGD

Table 2. Study participants.

\begin{tabular}{|c|c|c|c|c|c|c|c|c|c|c|c|c|c|}
\hline Levels $\rightarrow$ & National & Province & District & & & & & & Village & & & & \\
\hline \multirow{2}{*}{$\begin{array}{c}\text { Data Collection } \\
\text { Method } \\
\downarrow\end{array}$} & \multirow{2}{*}{$\begin{array}{l}\text { Implementers } \\
\text { (IN) }\end{array}$} & \multirow{2}{*}{$\begin{array}{l}\text { Implementers } \\
\text { (IP) }\end{array}$} & \multirow{2}{*}{$\begin{array}{l}\text { Implementers } \\
\text { (ID) }\end{array}$} & \multirow{2}{*}{$\begin{array}{l}\text { Private } \\
\text { (PR) }\end{array}$} & \multicolumn{4}{|c|}{ Implementers-The VNT (IV) } & \multirow[t]{2}{*}{$\begin{array}{l}\text { School } \\
\text { (SR) }\end{array}$} & \multicolumn{4}{|c|}{ Beneficiaries (B) } \\
\hline & & & & & Phouko & Mokloy & $\begin{array}{l}\text { Nam- } \\
\text { Khong }\end{array}$ & $\begin{array}{l}\text { Phonsa } \\
\text { At }\end{array}$ & & Phouko & Mokloy & $\begin{array}{l}\text { Nam- } \\
\text { Khong }\end{array}$ & $\begin{array}{c}\text { Phonsa } \\
\text { At }\end{array}$ \\
\hline FGDs $(n=11)$ & 1 & & & & 1 & 1 & 1 & 1 & & 1 & 1 & 2 & 2 \\
\hline FGD participants & 4 & & & & 6 & 7 & 5 & 5 & & 7 & 7 & 16 & 11 \\
\hline Interviews $(n=34)$ & 1 & 4 & 8 & 1 & 0 & 1 & 0 & 0 & 2 & 2 & $\begin{array}{c}6(1 \\
\text { male })\end{array}$ & 3 & 6 \\
\hline $\begin{array}{c}\text { Total } \\
(n=101)\end{array}$ & 5 & 4 & 8 & 1 & 6 & 7 & 5 & 5 & 2 & 9 & 14 & 19 & 17 \\
\hline
\end{tabular}

\subsection{Data Collection}

The primary data were collected using 11 focus group discussions (FGDs) and 34 semistructured interviews (SSIs). The FGDs were administered at the national level with the project implementers and the village level with VNTs and beneficiaries. The SSIs involved project implementers at all levels, key informants, and beneficiaries. The FGDs and SSIs were guided by semi-structured tools refined based on the collected information. The tools mainly covered two aspects: the effects of the project on food security and nutrition; and barriers and facilitators to project implementation. The tools can be accessed from our another paper [16]. While this paper focuses on the impact pathways, factors, i.e., either barriers or facilitators to the project implementation will be presented in another paper.

We administered the tools in the Laotian language. When beneficiaries only spoke the ethnic languages, such as Hmong, we mobilized local translators. Data were collected by trained researchers and tape-recorded. We stopped collecting the data when there was saturation, i.e., when no new information on the pathways emerged. The average duration of the FGDs with implementers and beneficiaries was around $90 \mathrm{~min}$. The interviews with implementers, beneficiaries, school representatives, and private sector representatives lasted on average $78,57,43$, and $40 \mathrm{~min}$, respectively. The duration of the interviews 
differed because of differences in the involvement of the participants in the project. School representatives and private sector parties had less knowledge about the project, and hence, the interview with them was shorter.

The primary data were supplemented by a desk review of ENUFF Project documents. The main objective of the desk review was to support theory building and triangulation [29]. The review contributed to building effects on nutrition outcomes as these are best studied by quantitative methods. The documents analysis also served to triangulate data on pathways.

The desk review involved four key steps. The first was the identification of all documents of the ENUFF Project reporting on project results on nutrition (or WASH)related outcomes or pathways. We identified five documents to include in the review. Of these, three were either end-line reports or learning briefs that used quantitative data on effects and/or pathways $[25,27,30]$. One was a learning brief that used both qualitative and quantitative approaches [26]. The remaining one was a gender and social inclusion analysis report 2019 that applied qualitative methods [31]. The documents included in the desk review are as follows:

1. ENUFF Project learning brief No. 5, Nutrition-sensitive agriculture for improved dietary diversity, June 2021 [25]

2. ENUFF project end line report, July 2020 [30]

3. ENUFF Project learning brief No. 4, Water, Sanitation and Hygiene (WASH) related determinants of under-nutrition, June 2020, [27]

4. ENUFF Project learning brief No. 3, Promoting positive behaviours in nutrition through community volunteers, June 2020 [26]

5. ENUFF Gender and Social Inclusion Report, November 2019 [31]

For clarity in interpretation, data from desk reviews that are not covered by primary data are linked to the respective documents in the results section.

The three remaining phases of the desk review process were skimming of documents, thorough reading, and interpretation [29]. We integrated the data from the desk review with the primary data during data analysis. The data extracted from the documents are illustrated in Supplementary Material S2.

\subsection{Data Analysis}

The audio-recorded FGDs and interviews were transcribed and translated from Laotian to English at the same time by the person involved in data collection and fluent in both languages. The transcripts in the local ethnic language were first translated into Laos and then to English. A directed content analysis of this embedded case study was carried out using ATLAS.ti version 8.4.4 in four phases. In the first phase, the FGDs and interviews were cumulatively coded by reading the transcripts thoroughly to develop initial codes on the effects on nutrition and the pathways to the outcomes using a framework by Sharma et al. (2021) [3]. Two researchers were involved in the coding. The coding on the effects focused on five themes-household living environment, care and WASH practices, dietary practices, the prevalence of diseases, and nutritional status of children. Similarly, we coded the pathways to these outcomes from interventions across five themes: (i) food production, (ii) nutrition-related knowledge, (iii) agricultural income and nutrition-related expenditure, (iv) women's empowerment, (v) and strengthening of local institutions (3). In line with the scope of the ENUFF Project, we considered the first three as core pathways whereas women's empowerment and strengthening of local institutions supported the core pathways. We further adopted the nutrition and WASH-related knowledge pathway to the 'nutrition and WASH-related knowledge and WASH infrastructural development' pathway based on the project's scope and available data. During the second phase, we supplemented the primary data with the results of the desk review, which was also analysed using the same coding structure. While the primary qualitative data dominated the results on pathways, the findings on the effects mainly came from quantitative data used in the desk review. In the third phase, we created impact pathways for each village. As this was an embedded case study, the sub-unit of analysis for coding was each of the four villages. 
By the end of the third phase, all four villages had their pathways. In the fourth phase, we construct a general pathway by integrating village specific data and the data from the district, province and national levels.

\subsection{Ethical Considerations}

Our research involving the primary data collection received ethical clearance from the National Ethics Committee for Health Research (NECHR), Lao Tropical and Public Health Institute under the Ministry of Health, Lao PDR. We obtained written informed consent from all the participants.

\section{Results}

In this section, we first present the effects of the ENUFF project on nutrition-related outcomes and then describe the pathways to the effects. Together, they make the impact pathways from the project activities to nutrition. The overall impact pathways are illustrated in Figure 1 with the village-specific pathways provided in Supplementary Material S1.

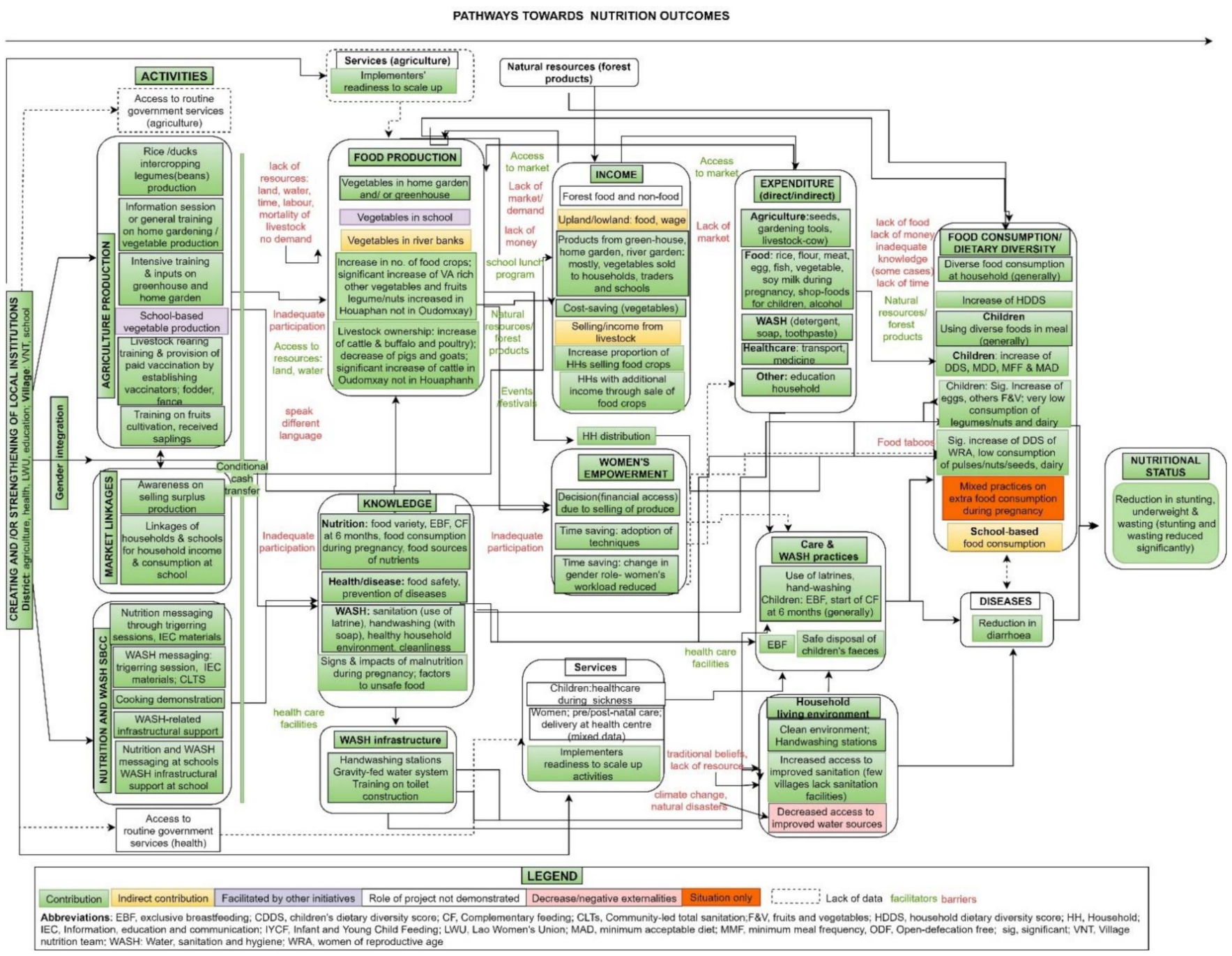

Figure 1. Results on pathways from NSA interventions towards nutrition outcomes, using Sharma et al., 2021 [3].

\subsection{Effects on Nutrition-Related Outcomes}

This section describes the effects on five levels of outcomes: household living environment, care and WASH practices, dietary practices, the prevalence of diseases, and the nutritional status. 


\subsubsection{Household Living Environment}

The project recorded an improvement in the household living environment in terms of sanitation facilities. The number of 'open defecation free' villages and the proportion of households with access to improved sanitation facilities increased from 3 to 24 [27], and $75 \%$ to $92 \%$ [30], respectively. The reasons for some of the houses not having a toilet were traditional belief, lack of interest or lack of resources such as money, water or labor. According to an implementer,

"Some of the villages don't have water access such as Phouko where the water access is very limited and some of the villagers don't even have water access or too far from the water source or no equipment or money, then that's just how it is. [...] Their own usual habit, which is to open-defecate in the forest because they think it is convenient and that they don't need to wash it."

The proportion of households with access to an improved water source, however, decreased from $98 \%$ in the baseline to $90 \%$ in the end line [30]. Nevertheless, 2 out of 4 study villages had access at $100 \%$ [30]. Of the villages, Phouko had the least accessibility to water. The main reasons mentioned for this are either change in the climate drying up the sources or destruction of gravity-fed water systems by natural disasters [30]. Qualitative data also stresses a lack of water or improper management of water as an important problem.

\subsubsection{Care and WASH Practices}

The project contributed to improve care practices concerning exclusive breastfeeding and sanitation and hygiene practices among mothers. The proportion of exclusively breastfed children and the practice of safe disposal of child feces increased from $53 \%$ to $97 \%$, and $32 \%$ to $67 \%$, respectively [30]. Qualitative data also reveals exclusive breastfeeding practices, improved handwashing practices, and improved use of a toilet.

\subsubsection{Dietary Practices}

The project recorded an improvement in dietary practices at three levels: household, children and women.

At the household level, the mean dietary diversity score (DDS) increased from 2.7 at baseline to 3.9 at end line [30]. These findings are well supported by qualitative accounts. Several beneficiaries reported that they changed their food consumption by adding variety to their meal. Most of these beneficiaries used at least three food groups, as indicated in the following quote.

"[About] five food groups, sometimes they are not complete. [...] When there are some, found some, we would have complete five groups but if not, there would only be about three groups."

End line comparison across intervention and non-intervention villages showed a significantly higher score in Houaphanh province only and not in Oudomxay [25]. The reasons for limited dietary diversity were lack of food, money, or knowledge in a few cases.

The project recorded an overall improvement in children's dietary practices with variations across villages and types of indicators [30]. The mean dietary diversity score of children 6-23 months of age increased from 2.8 in baseline to 4.0 in end line [30]. Similarly, the proportion of children practicing minimum acceptable diet, minimum meal frequency, and minimum dietary diversity increased from baseline to end line with the following changes: $1 \%$ to $59 \%, 14 \%$ to $66 \%$, and $23 \%$ to $72 \%$, respectively [30]. However, the practices varied across four villages. While all four villages recorded an improvement in the minimum acceptable diet, other indicators either progressed or remained the same or declined in some villages [30]. 
Among children, the disaggregated data on food consumption based on endline comparison across intervention and non-intervention villages varied across geographical areas and food groups [25]. The consumption of eggs and other fruits \& vegetables was significantly higher in intervention villages. Children frequently consumed grains, roots \& tubers, flesh foods, and breast milk [25]. However, the consumption of legumes \& nuts, and dairy was extremely low. The effect on DDS also varied across the province with the significant improvement in Houaphanh province (4.16 vs. 3.46, $p<0.05$ ) whereas Oudomxay showed no significant change ( 3.98 vs. 3.89, $p>0.05$ ) [25]. The reasons behind the inadequate dietary diversity explored through qualitative data were lack of time, food, money or knowledge. Nevertheless, there was an overall improvement in the feeding practices. As discussed during an FGD in Phonsa At,

"No, I didn't do the same [before and after the project] after the staff came and did the demonstration, I would often cook it." [P1] "When they are 0-6 months, I would only give breastmilk, and after 6 months, I would cook rice porridge for the baby. [...] Put in the rice, vegetable and sliced pork, also pumpkin, and a bit of salt."

[P3] [BF-3]

End line report does not provide information on women's dietary practices. Comparative assessment of the DDS between intervention and non-intervention households in the end line indicates the significantly higher DDS of women of reproductive age in intervention villages in both provinces $(p<0.05)$, Houaphanh (5.00 vs. 3.89) and Oudomxay (4.22 vs. 3.37) [25]. The women mostly consumed grains, roots and tubers, vegetables, and meat, poultry and fish. However, there was a very low consumption of pulses, nuts and seeds, dairy, and eggs (see Supplementary Material S2).

Qualitative data did not provide information on the effects but only on the situation on practices before and during pregnancy. The data illustrates mixed practices as some participants increased consumption during pregnancy while others did not. Health care facilities during antenatal care check-ups facilitated the consumption by providing information. However, lack of food and money and prevailing food taboos hindered food consumption during pregnancy and/or postnatal periods. According to a beneficiary,

"[The consumption pattern] was like usual. The extra thing I added was when I had money, I would go and buy some fruits to eat. Of course, I increased my consumption of fruits and anything that would be beneficial for the baby. Buying Anne-Mum (maternal milk) as well. When I don't have money then I don't buy."

[BF-3]

\subsubsection{Prevalence of Diseases}

The incidence of diarrhoea among children less than 2 years of age reduced from $24 \%$ at baseline to $13 \%$ in the end line [30] with all four villages reporting the reduction. One FGD also indicated a reduction in diseases among children, as stated in the following passage,

"Of course, it [reduction in diseases] has increased. Why? It is because, one, it has built our immune system to be better so that we don't get sick, for our children to grow bigger and better. [...] Our children get to attend school and they have no sickness."

[P2, IV-2]

\subsubsection{Nutritional Status}

The project contributed to an overall reduction in undernutrition [30]. The prevalence of stunting, underweight, and wasting reduced from baseline to end line with the following values: $42.3 \%$ to $37.7 \%, 28.6 \%$ to $23.1 \%$, and $10.7 \%$ to $5.2 \%$, respectively [30]. Of these, stunting and wasting were significantly reduced in the end-line compared to baseline $(p<0.05)$ [30]. However, effects varied across villages, as illustrated by descriptive data [30]. While all four villages witnessed a decrease in stunting, change in underweight and wasting varied across the villages. Prevalence of underweight decreased in Phonsa At but increased 
in Namkhong [30]. Likewise, the prevalence of wasting decreased in Phonsa At, Mokloy and Phouko but increased in Namkhong [30].

An FGD and an interview indicated an improvement in the nutritional status of children based on their anthropometry. According to a VNT,

"Previously, children were thin, malnourished. After the project came, they have access to vegetables and meat for their children to eat and when they did their height and weight measurement, and they passed [... ] Yes, for this we have seen from the results."

[P1, IV-4]

\subsection{Pathways from NSA Interventions to Nutrition Outcomes}

As illustrated in Figure 1, the different units of the analysis together expose five pathways present from the interventions to nutrition-related effects described in an earlier section. These are food production, agricultural income, nutrition-related knowledge, women's empowerment, and the strengthening of local institutions. The village-specific pathways are illustrated in Supplementary Material S1.

\subsubsection{Food Production}

The project contributed to the adoption of vegetable production techniques that increased the variety and quantity of vegetables in the home garden and greenhouse. The production was better in the greenhouses where beneficiaries could produce throughout the year. Beneficiaries mostly used the produce for consumption and some beneficiaries also sold surplus to generate income, as illustrated in the following quote.

"We all had a little bit before the project came. Only enough for family consumption" [P3] "Iust a little one until the project came then we expanded and did more. It's now enough for both consumption and for selling ... " [P7] "Compared to last year, they look nicer ... " [P4] "They came, trained us, and provided some seeds, hoe and watering can. They grow much better and can be sold and consumed by many families."

[P7] [BF-5]

More households owned home gardens and poultry and produced more quantity and variety of crops, including vitamin A-rich and other fruits and vegetables. While the production of legumes or nuts also improved, this recorded very low production with significant improvement in the Houaphanh province only [25].

In the livestock category, beneficiaries raised cows, buffaloes, pigs, goats, dogs, chickens and ducks. The training on livestock production and paid vaccinations improved livestock ownership to some extent.

"[Translator] she said she's been raising them before ENUFF came but she didn't have many and then after ENUFF came, they taught ways to take care of the livestock and so it has been improved."

The end-line report reveals increased ownership of cattle and buffalo, goat, and poultry, whereas the ownership of pigs decreased [30]. When compared across intervention and non-intervention households at the end line, both Houaphanh and Oudomxay provinces recorded significantly higher ownership of poultry, whereas big livestock ownership was significantly higher in Oudomxay province only [25].

The pathway leading to livestock production was constrained due to the mortality of livestock, mostly poultry. A few participants suggested the need for a better focus on livestock because of their high mortality. A need to focus on livestock in the households that lack land to produce vegetables was also stated. According to an implementer,

"Pigs and others are still okay. When we visited some of the villages, they all said their poultry died." 
The production varied across villages and specific agricultural products. Several beneficiaries in the lowland commercial village had a home garden before the project, and some households in remote upland started the gardens as a result of the project's activities. Most of the beneficiaries who already had a home garden expanded it, applying the lessons, and produced more. A few beneficiaries, however, stated that the production remained the same. The household food security based on endline comparision across intervention and non-intervention households also saw varying effects with significant positive results in Oudomxay but contradictory results in Houaphanh [25]. Based on endline descriptive data, all four study villages recorded an increase in the mean number of food crops and ownership of cattle/buffalo, goal and poultry [30]. However, three of these villages recorded a decrease in the proportion of households producing food crops or owning pigs [30].

The attempt to make the beneficiaries adopt and/or continue the home gardening practices were affected by several barriers. Adapting home gardens and producing its produce was affected by low participation of women in training, lack of resources such as land, time, labour, or water, and poor access to buyers/lack of demand. The insufficient access to land and/or water led to gardening near riverbanks for some households. The following quote highlights lack of time as a barrier,

"First of all, I have to make money for my children, secondly for our house, family and our livestock, plus the food is also dependent on me. However, I still do it [home garden] but only once or twice, only this dry season that I do not have enough time to do it yet. I still did it, sold two sets already, but I have not started the third set yet."

A few beneficiaries mentioned the spill-over effects of the production of vegetables experienced in two ways: diffusion of production-related knowledge, skills or inputs from pilot farmers to other beneficiaries; or application of seeds in the gardens at riverbanks or upland/lowland farms. For example,

"Since my vegetables didn't look as nice, I went to see theirs and they told me the methods on how to grow them nicely with good quality and I would follow the methods that they've taught me. The result was that the products look better now ... I was able to sell and consume some as well."

It is noteworthy that agricultural production at upland and lowland farms and forests were sources for food consumption and income. In the upland and lowland farms, beneficiaries cultivated crops such as grains, legumes, nuts, vegetables and fruits, and some raised livestock. Some beneficiaries revealed a reduced yield of products in these fields, especially of rice due to heavy rainfall preventing traditional fertilization methods (slash and burn), weeds, or the death of crops. Besides producing the food in the farms, the beneficiaries also relied on the forest to forage vegetables, meat and fish.

The contribution of the production pathway to dietary diversity varied across target populations and specific production-related indicators [25]. The number of food crops and food security resulted in better dietary diversity of women of reproductive age [25]. However, the variables on the production of food crops or livestock considered by the study included in the desk review did not predict children's DDS. Furthermore, several other included variables, such as having a home garden or livestock ownership did not influence any of these DDS scores. This highlights the role of NSA and that agricultural production alone may not improve dietary diversity [25].

\subsubsection{Agricultural Income and Nutrition-Related Expenditure}

Besides being a source of food, agriculture was also a source of income that allowed beneficiaries to make nutrition-related expenses. There was an increase in income from the products grown at the home garden and greenhouse in two ways. First, growing food instead of spending money to buy led to savings. Second, the better yield of diverse 
and quality crops contributed to increases in the selling of vegetables, mostly among greenhouse recipients. Besides the increase in the production of vegetables, the end line report indicates an increase in the proportion of households selling food crops [30]. Almost half of the participants of qualitative research who sold the products linked it to the project's contribution. There were also some who responded that they do not sell any products while a few reported a decline in selling due to reduced demand.

"Before this, there were about 4-5 families that were selling vegetables and after the project was implemented, we could see that there are more families who are selling vegetables." [P5] [... ]"More than 20 families [are selling]" [P5]. "About 50 families actually"

[P1] [IV-2]

Beneficiaries reported three channels for selling: other villagers for home consumption or special events such as festivals and weddings, schools for the school lunch program, and mobile traders (in Phonsa At village). Recipients of the greenhouse experienced the most benefit as they could produce and sell the products throughout the year. They also benefited from high food prices during the lean period. According to a greenhouse beneficiary,

"Now it [income from selling vegetables] has increased to [double] [... ] [Particularly] the Chinese cabbage because nobody in the village has any. Only us. So, they would come and buy from us."

Regarding income from livestock, a few beneficiaries reported selling livestock such as buffalo, pigs and goats occasionally to invest in productive assets such as a house, tractor, rice mill or a cow, while buying for own consumption in small quantities from the market. Big livestock was generally kept as a means for financial safety [25]. A few participants also indicated the consumption of poultry meat which they themselves produced and the qualitative data lack information on the selling of poultry. Although there was an increase in livestock ownership, the impact on selling or income from livestock was not clear from the qualitative data.

The income contributed to nutrition-related expenses, such as food, transportation to access health care, WASH and agricultural production. The expenditure on food by the beneficiaries was made for meat, salt, herbs and spices, vegetables, fish, soy milk during pregnancy, packaged foods or candies for children available at shops, rice, flour, egg, legumes/beans, fruits, and alcohol. Beneficiaries also used the income on water and electricity (bills), clothes, education for children and other household purposes. The following saying from a greenhouse beneficiary illustrates how she used the income from selling vegetables to purchase other food items.

"When I sell vegetables and earn some money, I use that money to buy meat or eggs if we feel like it."

The income to expenditure pathway was affected by access to the market, which varied across villages. In Phouko, a very remote and upland village, beneficiaries scantly practised selling. When they sell the vegetables, they had to take them to the open ground and yell, "please buy vegetables from me". In Mokloy village, beneficiaries practised exchanging amongst themselves due to the lack of external buyers. These villages also lacked a market to buy meat. In Namkhong, several beneficiaries were willing to sell but did not have external buyers due to which they were not able to sell all the surplus products. The lack of buyers demotivated them to produce a surplus. The selling was better in Phonsa At, a lowland village with road access as beneficiaries could sell vegetables to external traders. Both Namkhong and Phonsa At villages also had access to meat and/or fish supplied by mobile traders.

The significant sources of income for several beneficiaries were upland/lowland farm, forest and wage labour. They practised selling food and non-food items collected from these areas. Some of them also earned money from wage labour in farms. Although these 
sources are beyond the direct scope of the project, they facilitate the income-expenditure pathway. Food-related expenditure was also affected by access to money.

3.2.3. Nutrition and WASH-Related Knowledge and WASH Infrastructural Development

Several beneficiaries learned about at least one of the nutrition and WASH-related topics. The topics were: diverse food consumption, extra food consumption during pregnancy, breastfeeding, complementary feeding, harmful effects of using foods produced using chemicals, proper cooking techniques/procedures, and food sources of nutrients such as vitamins and protein (few beneficiaries). The participants knew about the need to eat varieties of food. The specific knowledge of the required number and name of the food groups was, however, inconsistent. The WASH-related knowledge gain comprised topics of hygiene, clean household environment, consequences of open defecation or use of the toilet, and washing hands with soap. Beneficiaries' knowledge of nutrition and WASH varied across villages [30] (see Supplementary Material S2). The following passage shows how knowledge influenced food consumption.

"They said for each day, we should consume six food groups or if we don't have all the groups then at least 4 groups. If today we are eating vegetables, the [meal] should also include meat, potatoes, corns, etc. However, I am trying to consume at least four groups: vegetables, meat, bamboo shoots. [ ... I If there is no rice, then we can use corns as a substitute, or potatoes or taros as a substitute. The vegetable oil replacement types are peanuts. Animal oil or peanuts. [ ... ] I just know when the project came."

There was an improvement in the acquired knowledge. The knowledge of the nutrition pathway was, however, constrained due to three reasons. First is the lack of knowledge acquisition by the beneficiary because the information did not reach them due to a lack of participation of women or a lack of sharing from other household members who participated in the activities. Second, some participants admitted having forgotten some nutrition-related messages. The third reason is the inadequate translation of the acquired knowledge into practice. Dietary diversity was affected by a lack of production, money, market, or time. Likewise, knowledge of sanitation alone did not motivate some beneficiaries to construct a toilet.

There were a few cases of diffusion of knowledge either from the direct participants to nonparticipants or from other sources to the project participants. A few beneficiaries who did not participate in the cooking demonstration knew about diverse food consumption from their parents or other women participating in the activity. Furthermore, a government implementer also delivered some knowledge to non-target villages while executing regular activities. A few beneficiaries also gained knowledge from healthcare facilities during antenatal care visits, school or television.

The project improved access to WASH facilities, such as toilets, handwashing stations and water systems. The village recorded an improvement in access to sanitation facilities, with the number of open defecation-free villages also increasing to 24 in 2019 compared to 3 in 2016 [27]. The project rehabilitated and/or constructed new water systems (gravityfed water systems. Still, several households had not constructed toilets due to lack of money, insufficient labour, traditional beliefs, or perception that the project would provide materials. According to an implementer,

"Their own usual habit which is to open-defecate in the forest because they think it is convenient and that they don't need to wash it."

The contribution of nutrition-related education or having WASH facilities on nutrition outcomes varied across indicators (see Supplementary Material S2). For example, women's education and access to improved water source were associated with DDS among women of reproductive age. However, they did not affect children's DDS [25]. Similarly, the 
contribution of WASH on nutrition outcomes also varied across specific practices or outcomes. Reduced open defecation, or improved access to safe water reduced diarrhoea [27]. Absence of animal faeces in household premises resulted in improved height-for-age z-scores [27]. Some other(s) did not play a role [27].

\subsubsection{Women Empowerment}

We identified two sub-pathways leading from women's participation to women's empowerment: intra-household decision making and resource allocation; and saving in time spent to access food or perform household work. Although the full impact on nutrition outcomes was not clear, we describe the change in the pathways in the following paragraphs.

Women's participation in the project activities is a crucial entry point to their empowerment. While several women participated in the activities, there were many occasions when other members of the household participated. The reasons for not participating were that women were busy with household or farm work; language was also a barrier. Furthermore, a few participants provided a perception of gender inequality:

"Because they are based on the fact that if they depend on the women, they wouldn't understand that well if I have to be truly honest. That's how we are most of the time. They would just be like, okay, just let the men go because the women wouldn't understand what they talk about. [ . . . ] Most of the time it would be men."

Men went to the activities on several occasions but failed to share their acquired knowledge with their wife, while she is the one taking care of the home gardens and preparing food for the household.

Regarding intra-household decision-making, women could decide on selling agricultural products and making household purchases using the money earned from selling food products irrespective of the project intervention. The beneficiaries, however, started selling more after the project intervention making them more financially empowered. GESI analysis states that women have a lesser hold in financial decision-making, especially on larger investments (>50,000 kips) [31]. During an FGD, participants indicated that, in a different context, deciding to construct a toilet was dependent upon the approval from the husband despite the interest of women beneficiaries.

A lack of own participation or a lack of information sharing from other household members who participated also affected nutrition-related decisions making as indicated by the following quote.

"And after he went to the training, did he come back home and cook for your children or change the way you used to cook or prepare food for your children?" [interviewer] "He is a man, so he does not really know how to cook. Mostly for dinner, it is me and the kids who would cook for him." [P1] "And he didn't tell what to put and all?" [interviewer] "No, he didn't."

[P1] [BF-6]

The project contributed to saving women's time in two ways. First, the adoption techniques such as home gardens or greenhouses saved time that was spent looking for vegetables from upland and lowland farms, forests, or the market. Second, a few participants stated that a greater awareness of gender equality led to husbands' contribution to household work. As a result, women were less involved in heavy workloads allowing more time for family. The following quote indicates saving in women's time.

"We have vegetables in our home garden so if we want to eat some, we can just go and collect from our home garden and don't need to go to the forest to find some. Save time so we can work for the family."

[P1, BF-3]

The translation of saving time may have contributed to better nutrition of their children as a lack of time was indicated as a key barrier for doing so. This translation needs further validation. 
Key barriers on this pathway were gender inequality leading to low participation of women, dependency upon men to access services such as antenatal care (for transportation) or men having final say on decision making [31]. The gender inequalities were more prominent in the Oudomxay province [31].

\subsubsection{Strengthening the Local Institution}

This pathway appears as a pathway to stimulate the previous four pathways. The project established a system at the village level and enhanced the technical capacity of provincial and district-level institutions on nutrition-sensitive agriculture. In the villages, the VNTs monitored beneficiaries' practices on food production and nutrition.

The village veterinary worker also provided paid vaccinations to the livestock. The provincial and district team was also aware of the agriculture-nutrition integration. An important challenge affecting this pathway was coordination across sectors and levels. A few VNTs also asked for more capacity to conduct activities and follow up with the beneficiaries. The following quote by a VNT demonstrates increased involvement in the field activities.

\section{"Ever since the project came, Health office, Agriculture office and the Lao Women Union came to provide training on nutrition for the women and children under two so that they know how to cook properly for their children that will benefit them and for their growth development."}

The project also integrated five project learnings into policy dialogue and increased the readiness of implementing partners to scale up the activities [30]. The involvement of the volunteers from VNT in counselling households also improved the relationship between the village and district-based teams [30] (see Supplementary Material S2).

\section{Discussion}

To contribute to addressing malnutrition in Northern Laos, ENUFF Project employed NSA interventions-agricultural interventions that integrated nutrition objectives and actions through a convergence approach. This enabled us to explore these pathways to nutrition outcomes using framework from Sharma et al. 2021 [3] —food production, agricultural income, nutrition and WASH-related knowledge, women's empowerment, and strengthening of local institutions. Using our qualitative research approach, we found that ENUFF's NSA interventions contributed to improving nutrition outcomes via three core pathways-food production, nutrition-related knowledge and WASH infrastructural development, and agricultural income, supported by strengthening of local institutions. Concerning women's empowerment, the interventions helped save their time and also contributed to their income. Our research does not capture a concrete translation of women's empowerment to nutrition-related practices, which need further investigation. We recommend sustaining the strengthened capacity of local institutions beyond the project cycle. NSA needs consideration of multiple pathways with a contextualized and tailored approach based on geographical context to address contributing barriers. Our research contributes to food system theories through a focus on the pathways from nutrition-sensitive food production to food consumption. Because of the scope of this research and the ENUFF Project, we do not capture other stages of food systems outlined by other studies such as, processing, distribution, or disposal [32,33].

ENUFF Project improved nutrition viz. improved care and dietary practices and reduced diarrhoeal diseases and undernutrition. The outcomes that varied need particular attention, for example, household living environment. Despite improvement in some hygiene and sanitation-related outcomes, inadequate sanitation facilities and a reduction in access to water need further attention as incorporating WASH in NSA interventions can enhance nutrition outcomes [5]. Other outcomes requiring attention are dietary practices, especially in children in Oudomxay; the least consumed food groups such as legumes and nuts, dairy products and eggs; and underweight. The low consumption can be due to the traditional dietary practices in which Lao people do not like milk livestock, or dry 
beans and consume them as legumes. Improving the change in the diet needs a shift from traditional dietary practices to a more nutrient-rich diet.

Our result on the significant reduction in stunting and wasting is different from past studies that highlight the strong effect of NSA on intermediate outcomes such as improving dietary diversity but limited impact on reducing stunting, wasting or underweight $[3,5]$. The reduction in our study may be due to the integration of components beyond food production that can address multiple determinants of determinants [5], such as nutrition-related social and behaviour change communication or WASH infrastructures. Nevertheless, the evaluation design without control groups at baseline and end-line may have biased the results, which recommends a rigorous evaluation design.

The project contributed to improved nutrition mainly through three core pathwaysfood production, agricultural income, and nutrition and WASH-related knowledge. Past studies also reported on some of these pathways from similar nutrition-sensitive home gardening projects, for example, food production and consumption [34-39], agricultural income and food-related expenditure [35,36,39], and nutrition-related knowledge and dietary practices $[36,37,39]$. The project also empowered women that led to financial access and savings in their time. The translation of empowerment to nutrition, however, is inconclusive from our research and needs further inspection. The project strengthened the capacities of local institutions and multisectoral coordination to deliver NSA interventions while contributing to other pathways within the project's scope.

The five pathways need further attention to maximize their contribution to nutrition. An important strategy for enhancing production would be to prioritize inadequate produces such as legumes/nuts and dairy as well as address the mortality of livestock. Livestock can also be a viable option for households that lack land to produce vegetables. The income contributed to nutrition-related expenditure across multiple determinants of malnutrition highlighted by UNICEF [40]. There is, however, a need to foster this pathway through sufficient income and access to the market. Likewise, enhancing the knowledge pathway requires more participation from beneficiaries and means to apply the knowledge. As strengthening of local institutions can lead to improved service delivery $[3,39,41,42]$, we recommend sustaining the developed institutional capacity and mechanisms beyond the project cycle to enhance agriculture and nutrition-related service delivery. Women empowerment needs special attention that we discuss separately in the next paragraph.

To further empower women and translate it to nutrition-related practices, we recommend strategies across stages from their participation to their empowerment to nutrition outcomes. Low participation of women can be addressed by designing NSA programs that require mandatory participation [31]. Within this pathway, the project contributed to saving women's time and increasing their income. More efforts are required to safeguard their time available for nutrition as a past study reported that NSA can experience a trade where women spend more time in agriculture resulting in insufficient time for domestic work and children's care [43]. Managing these trade-offs is crucial in the upland farming areas where women have less time due to their high mobility to upland and lowland farms. Further, it is important to translate these aspects of women's empowerment to their nutrition-related practices, such as allocating saved time for their own or children's care and feeding or deciding the income to make nutrition-related purchases. This may require changes in the intra-household dynamics on gender inequality as well as community sensitization. A concrete translation of these aspects of women empowerment to nutrition-related practices is not captured by our research. Comparatively, less clarity on this pathway could also be because gender issues were not factored across all project components in the first phase, whereas the second phase explicitly incorporated gender equality across all project components. We suggest further study on the translation of women's time-saving and their access to income to nutrition-related practices.

We highlight the need to combine multiple pathways to bring optimal nutrition outcomes [3]. Improving nutrition entails more than just access to food [5] to address multiple determinants of malnutrition. Furthermore, one pathway affects other(s). The pathways 
on production, income, knowledge or women's time influence each other to contribute to intermediate practices on care, diet, or WASH, eventually affecting undernutrition. NSA interventions, therefore, need to be strategic on how all beneficiaries at all times can adhere to nutrition-related behaviours. This might require contextualizing the best possible combination of the pathways. The pathways are thus, inter-connected and do not bring the desired effect on nutrition, in silo.

A tailored approach is required as the progress of the pathways and effects were highly contextual based on the specific indicator and implementation context. Past studies also highlighted the need for a contextual response [3,5,16,22]. The knowledge, production and income pathways developed better in the areas with access to roads and markets, which could be due to the greater availability of foods and market outlets [14,44]. Although the dietary diversity is affected by distance to market and village-type [25], a few indicators did not progress even in the villages closer to roads. Notably, indicators within the single pathway or outcome category varied across geographical areas, for example, knowledge, production of legumes/nuts, and ownership of big livestock. This leads to another argument that the pathways and effects are contextual across target areas as they are subject to several factors. Therefore, we stress the need to address multiple barriers affecting the pathways and effects such as low participation of women, lack of access to land, money, labour, water and market, mortality of livestock and food taboos. Some of these factors are consistently reported elsewhere, such as land [39,45,46], water [34,46], money [47,48] or market $[14,35,44,49]$. Addressing the barriers may benefit from a comprehensive analysis of the factors from an implementation perspective.

This study offers two main strengths. First, this is the first study on NSA that looks specifically at the context of the Lao PDR. A focus on the upland farming families, who have not been specifically covered by past studies, further adds to the knowledge. Second, the study uses multiple data sources to complement and/or validate the data. The use of quantitative data from desk review to describe effects and the use of qualitative data to explore pathways together contributed to mapping the pathways from interventions to nutritional status in a holistic way. Likewise, the use of qualitative and quantitative techniques on the pathways enabled the triangulation of the data. The research findings may have been affected by four limitations. The first limitation is the lack of generalizability of the conclusions made from the qualitative interviews and FGDs. To minimize the limitation, we reviewed project documents to validate or supplement the findings, which added strength to the research. Second, the documents included in the desk review can be subject to bias. Inadequate data on the pathways, the evaluation design without matching control groups, seasonal differences in data collection period at baseline and end-line, probability of selection bias in the end line due to COVID-19 situation [30], and a lack of control over participants or methods make the quantitative data used in the desk review less rigorous. Third, mobilization of implementers as translators due to unforeseen language barriers may have affected beneficiaries' responses leading to social desirability bias. The fourth limitation is the lack of a complete triangulation of primary data and desk review as they came from different periods. However, this choice was rational because, while the end-line quantitative data can portray actual effects, the pathways and their mechanisms can be well studied during the implementation. We have also reported the desk review data source with corresponding references in the results section to allow readers to interpret accordingly.

\section{Conclusions}

The ENUFF Project's NSA interventions contributed to improved nutrition mainly through three core pathways-food production, nutrition and WASH-related knowledge and agricultural income, supported by strengthening local institutions within the project's scope. Concerning women's empowerment, the interventions helped save their time and also contributed to their income. Further study is needed to investigate the translation of these aspects to nutrition-related practices. We suggest the need to execute strategies to sustain the mechanisms of engaging local institutions and their capacity. As these pathways 
influence each other, a combination of these can produce better nutrition outcomes. A contextualized design and implementation tailored based on geographical context, contributing factors, and effects and pathways can contribute to addressing malnutrition in Lao PDR and similar LMICs.

Supplementary Materials: The following are available online at https://www.mdpi.com/article/10.339 0/su132313414/s1, Supplementary Material S1. Villages specific pathways from interventions to nutrition outcomes; Supplementary Material S2. Summary of key documents included under desk review.

Author Contributions: Conceptualization, I.K.S., D.E., R.S. and J.E.W.B.; methodology, I.K.S., D.E. and J.E.W.B.; data collection, I.K.S., field support during data collection, R.S.; formal analysis, I.K.S.; validation (analysis of beneficiaries' data), Z.D.S.; provision of documents for desk review, R.S.; writing - original draft preparation, I.K.S.; review, D.E., V.F., R.S., Z.D.S. and J.E.W.B.; finalization of manuscript, I.K.S.; supervision, D.E., V.F. and J.E.W.B. All authors have read and agreed to the published version of the manuscript.

Funding: This research was funded by Erasmus Mundus Joint Doctorate (EMJD) Fellowship-Trans Global Health Erasmus Mundus Ph.D. Program 2013-0039. The funders had no role in the design of the study; in the collection, analyses, or interpretation of data; in the writing of the manuscript, or in the decision to publish the results.

Institutional Review Board Statement: The study was conducted according to the guidelines of the Declaration of Helsinki and approved by the National Ethic Committee for Health Research (NECHR) of Lao Tropical and Public Health Institute under the Ministry of Health, Lao PDR (research number 2019.5.MC).

Informed Consent Statement: Informed consent was obtained from all participants of the study.

Data Availability Statement: The data that support the findings of this case study is with the author(s). The data may be made available on reasonable request from the corresponding author, though not all data may be made available due to privacy or ethical restrictions.

Acknowledgments: The authors would like to sincerely thank the study participants for sharing their valuable time and experiences. The authors also are thankful to Deirdre McMahon, SNV's former Global Nutrition Advisor for her support to collaborate, and the team of SNV and ENUFF Project funded by SDC for their time and support during data collection.

Conflicts of Interest: The authors declare no conflict of interest.

\begin{abstract}
Abbreviations
BF, Beneficiaries FGD; BI, Beneficiaries interview; DDS, dietary diversity score; ENUFF, Enhancing Nutrition of Upland Farming Families; FGD, Focus group discussion; ID, Implementers at the district level; IYCF, Infant and young child feeding; IV, Implementers at village level; KP, Key informants -private sector; KS, Key Informants—school; LMICs, Low and middle-income countries; NSA, Nutrition-sensitive agriculture; VNT, Village nutrition team; WASH, Water, sanitation and hygiene.
\end{abstract}

\title{
References
}

1. Kadiyala, S.; Harris, J.; Headey, D.; Yosef, S.; Gillespie, S. Agriculture and nutrition in India: Mapping evidence to pathways. Ann. N. Y. Acad. Sci. 2014, 1331, 43-56. [CrossRef]

2. Ruel, M.T.; Alderman, H. Nutrition-sensitive interventions and programmes: How can they help to accelerate progress in improving maternal and child nutrition? Lancet 2013, 382, 536-551. [CrossRef]

3. Sharma, I.K.; Di Prima, S.; Essink, D.; Broerse, J.E.W. Nutrition-Sensitive Agriculture: A Systematic Review of Impact Pathways to Nutrition Outcomes. Adv. Nutr. 2021, 12, 251-275. [CrossRef]

4. Haselow, N.J.; Stormer, A.; Pries, A. Evidence-based evolution of an integrated nutrition-focused agriculture approach to address the underlying determinants of stunting. Matern Child Nutr. 2016, 12 (Suppl. S1), 155-168. [CrossRef]

5. Ruel, M.T.; Quisumbing, A.R.; Balagamwala, M. Nutrition-sensitive agriculture: What have we learned so far? Glob. Food Secur. 2018. [CrossRef]

6. Gillespie, S.; van den Bold, M. Agriculture, Food Systems, and Nutrition: Meeting the Challenge. Glob. Chall. 2017, 1, 1600002. [CrossRef]

7. Lao Statistics Bureau. Lao Social Indicator Survey II (LSIS II) 2017; Lao Statistics Bureau: Vientiane, Laos, 2018. 
8. Development Initiatives. 2020 Global Nutrition Report: Action on Equity to End Malnutrition; Development Initiatives: Bristol, UK, 2020.

9. Nanhthavong, V.; Epprecht, M.; Hett, C.; Zaehringer, J.G.; Messerli, P. Poverty trends in villages affected by land-based investments in rural Laos. Appl. Geogr. 2020, 124, 102298. [CrossRef]

10. Government of Lao PDR. National Nutrition Strategy to 2025 and Plan of Action 2016-2020; Government of Lao PDR: Vientiene, Laos, 2015.

11. FAO; IFAD; UNICEF; WFP; WHO. The State of Food Security and Nutrition in the World 2017: Building Resilience for Peace and Food Security; FAO: Rome, Italy, 2017; ISBN 978-92-5-109888-2.

12. Dyg, P.M. Understanding malnutrition and rural food consumption in Lao PDR. J. Food Compos. Anal. 2006, 19, 763-764. [CrossRef]

13. Hepp, C.M.; Bech Bruun, T.; de Neergaard, A. Transitioning towards commercial upland agriculture: A comparative study in Northern Lao PDR. NJAS Wagening. J. Life Sci. 2019, 88, 57-65. [CrossRef]

14. Broegaard, R.B.; Rasmussen, L.V.; Dawson, N.; Mertz, O.; Vongvisouk, T.; Grogan, K. Wild food collection and nutrition under commercial agriculture expansion in agriculture-forest landscapes. For. Policy Econ. 2017, 84, 92-101. [CrossRef]

15. Siliphouthone, I.; Yasunobu, K.; Ishida, A. Analysis of Food Security among Rain-fed Lowland Rice-Farming Households in Rural Areas of Lao PDR A Daily Calorie Intake Approach. Trop. Agric. Dev. 2016, 60, 14-20. [CrossRef]

16. Sharma, I.K.; Essink, D.; Fumado, V.; Mridha, M.K.; Bhattacharjee, L.; Broerse, J.E.W. What Influences the Implementation and Sustainability of Nutrition-Sensitive Agriculture Interventions? A Case Study from Southern Bangladesh. Sustainability 2021, 13, 12049. [CrossRef]

17. Bouapao, L.; Insouvanh, C.; Pholsena, M.; Armstrong, J.; Staab, M. Strategic Review of Food and Nutrition Security in Lao People's Democratic Republic; World Food Programme: Vientiane, Laos, 2016.

18. UNICEF. Mid Term Review National Nutrition Strategy Plan of Action 2016-2020: National Nutrition Commitee Secretariat; UNICEF: Vientiene, Laos, 2020.

19. Wilson, R.T. Status and prospects for livestock production in the Lao People's Democratic Republic. Trop. Anim. Health Prod. 2007, 39, 443-452. [CrossRef] [PubMed]

20. Alexander, K.; Case, P.; Jones, M.; Connell, J. Commercialising smallholder agricultural production in Lao People's Democratic Republic. Dev. Pract. 2017, 27, 965-980. [CrossRef]

21. Khammounheuang, K.; Saleumsy, P.; Kirjavainen, L.; Nandi, B.K.; Dyg, P.M.; Bhattacharjee, L. Section Two-Asia-Pacific RegionSustainable Livelihoods for Human Security in Lao PDR: Home Gardens for Food Security, Rural Livelihoods, and Nutritional Well-being. Reg. Dev. Dialogue 2004, 25, 203.

22. Gillespie, S.; Poole, N.; van den Bold, M.; Bhavani, R.V.; Dangour, A.D.; Shetty, P. Leveraging agriculture for nutrition in South Asia: What do we know, and what have we learned? Food Policy 2019, 82, 3-12. [CrossRef]

23. SNV. Converging for Improved Nutrition in Lao PDR. Enhanced Nutrition for Upland Farming Families (ENUFF); Technical Brief No. 1; Netherlands Development Organisation: Vientiane, Laos, 2017; Available online: https://snv.org/assets/explore/download/ enuff_-_converging_for_improved_nutrition.pdf (accessed on 5 January 2019).

24. Scholz, R.W.; Tietje, O. Embedded Case Study Methods: Integrating Quantitative and Qualitative Knowledge; Sage Publications: Thousand Oaks, CA, USA, 2002. [CrossRef]

25. SNV. Nutrition-Sensitive Agriculture for Improved Dietary Diversity. Learnings from the ENUFF Project; Technical Brief No. 5; SNV Netherlands Development Organisation: Vientiane, Laos, 2021; Available online: https://snv.org/assets/explore/download/ ENUFF-learning-brief-5.pdf (accessed on 2 August 2021).

26. SNV. Promoting Positive Behaviours in Nutrition through Community Volunteers: Using Community Volunteers to Reach Pregnant Women and Families with an Infant below 24 Months; Technical Brief No. 3; Netherlands Development Organisation: Vientiane, Laos, 2020; Available online: https://snv.org/assets/explore/download/snv_enuff_learning_brief_3_-_online.pdf (accessed on 5 August 2021).

27. SNV. Water, Sanitation and Hygiene (WASH) Related Determinants of Under-Nutrition; ENUFF Project Learning Brief No. 4, June 2020; Netherlands Development Organisation: Vientiane, Laos, 2020; Available online: https://snv.org/assets/explore/download/ snv_enuff_learning_brief_4_-_online.pdf (accessed on 5 August 2021).

28. SNV. Enhancing Nutrition of Upland Farming Families: Baseline Report (February 2017), 54; Netherlands Development Organisation: Vientiane, Laos, 2017; [Unpublished].

29. Bowen, G.A. Document Analysis as a Qualitative Research Method. Qual. Res. J. 2009, 9, 27-40. [CrossRef]

30. SNV. Enhancing Nutrition Of Upland Farming Families: Endline Report (July 2020); Netherlands Development Organisation: Vientiane, Laos, 2020; [Unpublished].

31. Malam, L. Enhancing Nutrition for Upland Farming Families (ENUFF) Gender and Social Inclusion Report Commissioned by SNV Laos with Funding from the Swiss Agency for Development and Cooperation; Netherlands Development Organisation: Vientiane, Laos, 2019; [Unpublished].

32. Delgado, L.; Schuster, M.; Torero, M. Quantity and quality food losses across the value Chain: A Comparative analysis. Food Policy 2021, 98, 101958. [CrossRef]

33. Pretorius, B.; Ambuko, J.; Papargyropoulou, E.; Schönfeldt, H.C. Guiding Nutritious Food Choices and Diets along Food Systems. Sustainability 2021, 13, 9501. [CrossRef]

34. Birdi, T.J.; Shah, S.U. Implementing Perennial Kitchen Garden Model to Improve Diet Diversity in Melghat, India. Glob. J. Health Sci. 2015, 8, 10-21. [CrossRef] 
35. Bushamuka, V.N.; de Pee, S.; Talukder, A.; Kiess, L.; Panagides, D.; Taher, A.; Bloem, M. Impact of a homestead gardening program on household food security and empowerment of women in Bangladesh. Food Nutr. Bull. 2005, 26, 17-25. [CrossRef]

36. Jones, K.M.; Specio, S.E.; Shrestha, P.; Brown, K.H.; Allen, L.H. Nutrition knowledge and practices, and consumption of vitamin A-rich plants by rural Nepali participants and nonparticipants in a kitchen-garden program. Food Nutr. Bull. 2005, 26, 198-208. [CrossRef]

37. Murty, P.V.V.S.; Rao, M.V.; Bamji, M.S. Impact of Enriching the Diet of Women and Children through Health and Nutrition Education, Introduction of Homestead Gardens and Backyard Poultry in Rural India. Agric. Res. 2016, 5, 210-217. [CrossRef]

38. Olney, D.K.; Talukder, A.; Iannotti, L.L.; Ruel, M.T.; Quinn, V. Assessing impact and impact pathways of a homestead food production program on household and child nutrition in Cambodia. Food Nutr. Bull. 2009, 30, 355-369. [CrossRef] [PubMed]

39. Olney, D.K.; Vicheka, S.; Kro, M.; Chakriya, C.; Kroeun, H.; Hoing, L.S.; Talukder, A.; Quinn, V.; Iannotti, L.; Becker, E.; et al. Using program impact pathways to understand and improve program delivery, utilization, and potential for impact of Helen Keller International's homestead food production program in Cambodia. Food Nutr. Bull. 2013, 34, 169-184. [CrossRef]

40. United Nations Children's Fund (UNICEF). Strategy for improved nutrition of children and women in developing countries. Indian J. Pediatr. 1991, 58, 13-24. [CrossRef]

41. Gelli, A.; Margolies, A.; Santacroce, M.; Roschnik, N.; Twalibu, A.; Katundu, M.; Moestue, H.; Alderman, H.; Ruel, M. Using a Community-Based Early Childhood Development Center as a Platform to Promote Production and Consumption Diversity Increases Children's Dietary Intake and Reduces Stunting in Malawi: A Cluster-Randomized Trial. J. Nutr. 2018, 148, 1587-1597. [CrossRef]

42. Girard, A.W.; Grant, F.; Watkinson, M.; Okuku, H.S.; Wanjala, R.; Cole, D.; Levin, C.; Low, J. Promotion of Orange-Fleshed Sweet Potato Increased Vitamin A Intakes and Reduced the Odds of Low Retinol-Binding Protein among Postpartum Kenyan Women. J. Nutr. 2017, 147, 955-963. [CrossRef]

43. Kumar, N.; Nguyen, P.H.; Harris, J.; Harvey, D.; Rawat, R.; Ruel, M.T. What it takes: Evidence from a nutrition- and gendersensitive agriculture intervention in rural Zambia. J. Dev. Eff. 2018, 10, 341-372. [CrossRef]

44. Keokenchanh, S.; Kounnavong, S.; Tokinobu, A.; Midorikawa, K.; Ikeda, W.; Morita, A.; Kitajima, T.; Sokejima, S. Prevalence of Anemia and Its Associate Factors among Women of Reproductive Age in Lao PDR: Evidence from a Nationally Representative Survey. Anemia 2021, 2021, 8823030. [CrossRef] [PubMed]

45. Diana, R.; Khomsan, A.; Sukandar, D.; Riyadi, H. Nutrition extension and home garden intervention in posyandu: Impact on nutrition knowledge, vegetable consumption and intake of vitamin A. Pak. J. Nutr. 2014, 13, 88-92. [CrossRef]

46. Van den Bold, M.; Kohli, N.; Gillespie, S.; Zuberi, S.; Rajeesh, S.; Chakraborty, B. Is There an Enabling Environment for NutritionSensitive Agriculture in South Asia? Stakeholder Perspectives from India, Bangladesh, and Pakistan. Food Nutr. Bull. 2015, 36, 231-247. [CrossRef]

47. Doocy, S.; Cohen, S.; Emerson, J.; Menakuntuala, J.; Jenga Jamaa, I.I.S.T.; Santos Rocha, J. Food Security and Nutrition Outcomes of Farmer Field Schools in Eastern Democratic Republic of the Congo. Glob. Health Sci. Pr. 2017, 5, 630-643. [CrossRef] [PubMed]

48. Olney, D.K.; Pedehombga, A.; Ruel, M.T.; Dillon, A. A 2-Year Integrated Agriculture and Nutrition and Health Behavior Change Communication Program Targeted to Women in Burkina Faso Reduces Anemia, Wasting, and Diarrhea in Children 3-12.9 Months of Age at Baseline: A Cluster-Randomized Controlled Trial. J. Nutr. 2015, 145, 1317-1324. [CrossRef]

49. Dulal, B.; Mundy, G.; Sawal, R.; Rana, P.P.; Cunningham, K. Homestead Food Production and Maternal and Child Dietary Diversity in Nepal: Variations in Association by Season and Agroecological Zone. Food Nutr. Bull. 2017, 38, 338-353. [CrossRef] [PubMed] 